\title{
Improved quantification of absolute and differential pulmonary flow with highly- accelerated 4D-PC MRI
}

Albert Hsiao ${ }^{1 *}$, Tashfeen Ekram², Marcus T Alley², Frandics Chan², Beverley Newman², Shreyas Vasanawala ${ }^{2}$

From 18th Annual SCMR Scientific Sessions

Nice, France. 4-7 February 2015

\section{Background}

Conventional, planar phase-contrast (2D-PC) imaging is the gold standard for non-invasive measurement of blood flow, routinely used in the assessment of structural heart disease by MRI. Nevertheless, at many

institutions, nuclear perfusion scintigraphy (NPS) remains necessary for confirmation of differential pulmonary perfusion, but requires an additional exam with radiation exposure, and in younger children prolongs cardiac anesthesia. Highly-accelerated 4D phase-contrast

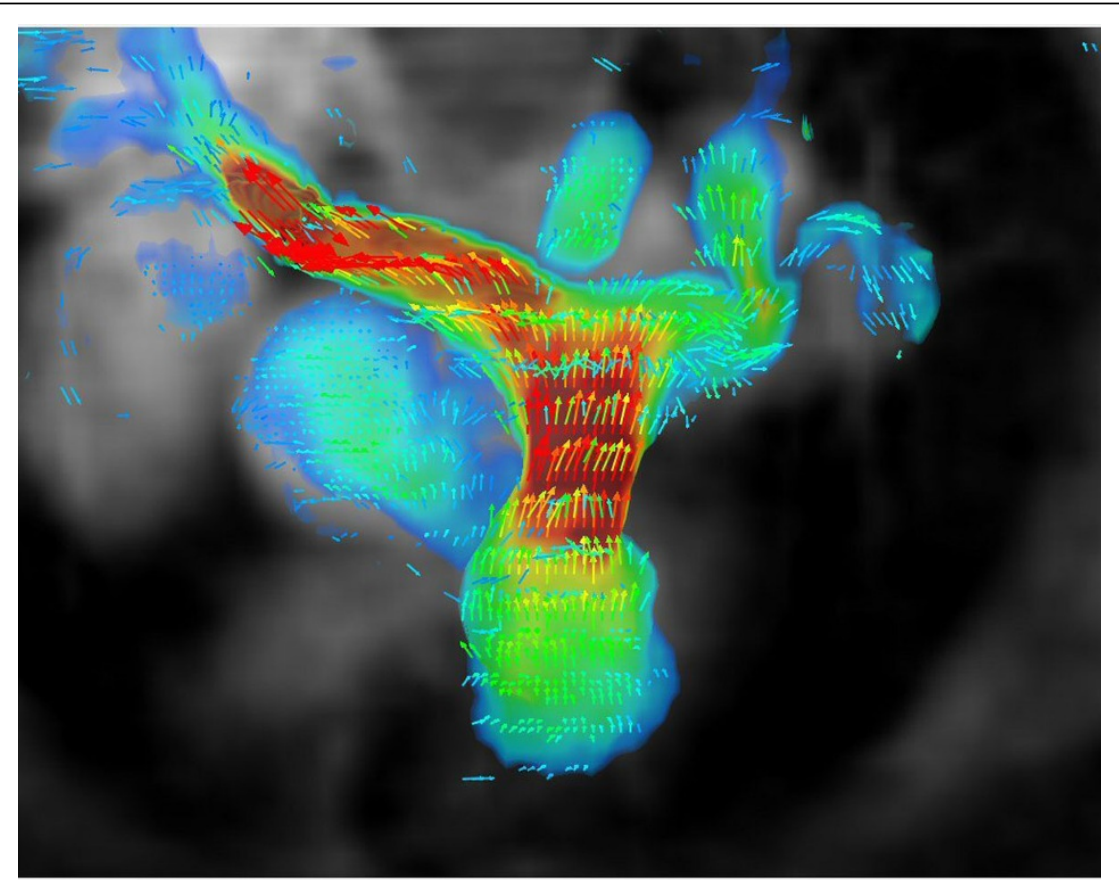

Figure 1 Cranial view of the pulmonary arteries in a patient with repaired Tetralogy of Fallot. Differential pulmonary perfusion by 4D-PC was measured at $58 \%$ to the right lung and $42 \%$ to the left lung, while regurgitant fraction at the pulmonary valve was measured at $39 \%$. By nuclear scintigraphy, split perfusion was measured at $65 \%$ to the right lung and $35 \%$ to the left lung.

$\overline{1}$ Department of Radiology, University of California, San Diego, San Diego, CA,

USA

Full list of author information is available at the end of the article 
(4D-PC) MRI is an evolving technology that has potential to greatly simplify congenital heart MRI. We hypothesized that 4D-PC may be sufficient for quantification of differential pulmonary flow.

\section{Methods}

With IRB approval and HIPAA-compliance, we retrospectively identified patients who underwent NPS as well as a cardiac MRI with 4D-PC from October 2011 through February 2014 without major surgery between exams. A total of $264 \mathrm{D}-\mathrm{PC}$ examinations from 25 patients (15 male, 10 female) were identified. Aortic, main and branch pulmonary flow were quantified from 4D-PC. Pearson correlation and Bland-Altman analysis were used to analyze the quantitative consistency of 4D-PC data. The same analyses were then applied to compare differential pulmonary perfusion from 4D-PC against 2D-PC and NPS.

\section{Results}

There was strong consistency between aortic flow and pulmonary flow measurements obtained at the pulmonary valve or as the sum of the branch pulmonary arteries $(\rho=0.93,0.90)$. Differential pulmonary flow measurements obtained from 4D-PC and NPS largely agreed $(\rho=0.92)$, while correlation between 2D-PC and NPS was more modest $(\rho=0.74)$. MRI and NPS were better matched among patients without substantial pulmonary regurgitation $(\mathrm{RF}<20 \%, \mathrm{n}=15)$ whether obtained by $4 D-P C(\rho=0.97)$ or $2 D-P C(\rho=0.94)$. In contrast, the presence of substantial pulmonary regurgitation $(\mathrm{RF} \geq 20 \%, \mathrm{n}=11)$ more severely impacted the accuracy of 2D-PC $(\rho=0.47)$ than 4 D-PC $(\rho=0.89)$.

\section{Conclusions}

Highly-accelerated 4D-PC is a viable alternative to NPS for evaluation of differential pulmonary perfusion, and has decreased sensitivity to turbulent flow that otherwise limits the accuracy of conventional 2D-PC. Highly-accelerated 4D-PC may not only help simplify congenital cardiac MRI, but may obviate the need for a separate nuclear scintigraphic examination to confirm differential pulmonary perfusion.

\section{Funding}

Tashia and John Morgridge Faculty Scholar Fund. Lucas Foundation. NIH R01 EB009690, NIH P41 EB015891. General Electric, Sloan Research Fellowship, American Heart Association Grant \#12BGIA9660006, NVIDIA.

\section{Authors' details}

'Department of Radiology, University of California, San Diego, San Diego, CA, USA. ${ }^{2}$ Department of Radiology, Stanford University, Stanford, CA, USA.
Published: 3 February 2015

doi:10.1186/1532-429X-17-S1-Q93

Cite this article as: Hsiao et al:: Improved quantification of absolute and differential pulmonary flow with highly-accelerated 4D-PC MRI. Journal of Cardiovascular Magnetic Resonance 2015 17(Suppl 1):Q93.
Submit your next manuscript to BioMed Central and take full advantage of:

- Convenient online submission

- Thorough peer review

- No space constraints or color figure charges

- Immediate publication on acceptance

- Inclusion in PubMed, CAS, Scopus and Google Scholar

- Research which is freely available for redistribution

Submit your manuscript at www.biomedcentral.com/submit 